\title{
A thermodynamic approach to guide reactive element doping: Hf additions to $\mathrm{NiCrAl}$
}

\author{
Thomas Gheno ${ }^{1 *}$ (D) , Bi-Cheng Zhou ${ }^{2}$, Austin Ross ${ }^{2}$, Xuan Liu², Greta Lindwall ${ }^{2 \dagger}$, \\ Zi-Kui $\mathrm{Liu}^{2}$ and Brian Gleeson ${ }^{1}$ \\ ${ }^{1}$ Department of Mechanical Engineering and Materials Science, \\ University of Pittsburgh, Pittsburgh, PA 15261, USA \\ ${ }^{2}$ Department of Materials Science and Engineering, \\ Pennsylvania State University, University Park, PA 16802, USA \\ Email: thomas.gheno at gmail
}

This is a post-peer-review, pre-copyedit version of an article published in

Oxidation of Metals. The final version is available online at: https://doi.org/10.1007/s11085-016-9706-0

\begin{abstract}
A method based on thermodynamic modeling was developed to determine optimal amounts of $\mathrm{Hf}$ additions to $\mathrm{Al}_{2} \mathrm{O}_{3}$-forming, $\gamma-\gamma^{\prime} \mathrm{NiCrAl}$ alloys. The alloy ability to maintain $\mathrm{Hf}$ in solution was set by the $\mathrm{Hf}$ concentration required to form $\mathrm{HfO}_{2}$ at the oxygen activity defined by the alloy $/ \mathrm{Al}_{2} \mathrm{O}_{3}$ equilibrium. This Hf tolerance decreased with increasing temperature and increased with increasing $\gamma^{\prime}$ fraction. The latter was due to the higher solubility of $\mathrm{Hf}$ in $\gamma^{\prime}$, compared to $\gamma$. The validity of the procedure was evaluated by oxidizing a series of $\mathrm{NiCrAl}-\mathrm{Hf}$ alloys in dry air at $1000-1200{ }^{\circ} \mathrm{C}$. The experimental results followed the predicted trends, although the Hf tolerance tended to be overestimated. The applicability of the criterion, and potential routes for improved predictability, were discussed by considering the influence of the compositional changes occurring at the metal surface during the transient and steady-state stages of the oxidation process.
\end{abstract}

Keywords: Reactive elements; Thermodynamic modeling; Coatings; Hightemperature oxidation

\section{Introduction}

Reactive element (RE) addition to high-temperature materials is a widespread method of improving their oxidation resistance. Mechanistic and practical aspects of RE effects have been discussed extensively in the literature; reviews are found in Refs. [1-6] for example. Most common dopants include $\mathrm{Y}$, $\mathrm{Hf}$ and $\mathrm{Zr}$ in $\mathrm{Al}_{2} \mathrm{O}_{3}$-forming systems, $\mathrm{Ce}$ and $\mathrm{La}$ in $\mathrm{Cr}_{2} \mathrm{O}_{3}$-forming systems. Their influence on oxidation behavior takes multiple forms, some of which are still open to interpretation. In particular, REs are known to yield significantly slower scale growth and improved scale adhesion. Although the two effects are related since a thinner scale will produce less growth stress, RE effects on scale adhesion appear to be more important than reduced scaling rates in determining the lifetime of a thermally cycled material [7]. A commonly accepted view is that REs neutralize $S$ impurities and thus prevent a weakening of the metal/oxide interface [8-13]. Other aspects of improved scale adhesion are

\footnotetext{
${ }^{*}$ now at DEN-Service de la Corrosion et du Comportement des Matériaux dans leur Environnement, CEA, Université Paris-Saclay, 91191 Gif-sur-Yvette, France

${ }^{\dagger}$ now at Materials Science and Engineering Division, National Institute of Standards and Technology, Gaithersburg, MD 20899-8555, USA
} 
system-dependent, as they are related to the metal coefficient of thermal expansion, strength and microstructure, all of which influence the stress state and integrity of the metal-oxide assemblage. In particular, RE additions are known to mitigate interfacial void formation, which is often associated with scale spallation from $\beta$ $\mathrm{NiAl}$ and $\mathrm{FeCrAl}$ systems, but not necessarily $\mathrm{NiCrAl}$ or Ni-base superalloys [14]. MCrAlY systems $(\mathrm{M}=\mathrm{Ni}$, Co or both) typically benefit from the formation of $\mathrm{Y}$ oxide particles (pegs) at the base of the $\mathrm{Al}_{2} \mathrm{O}_{3}$ scale, which are thought to improve the scale adhesion via "mechanical keying" [1], although some disagreement exists as to their actual role [6].

As beneficial as REs may be when added in the right proportion, overdoping can have detrimental consequences on oxidation resistance. Not only does overdoping increase overall scaling rates, but more critically, it produces oversized pegs which may favor scale failure during thermal cycling $[15,16]$, or act as initiation sites for accelerated corrosion under sulfate [17] or oxide-sulfate deposits [18]. Controlling $\mathrm{RE}$ additions, together with impurities such as $\mathrm{S}$ or $\mathrm{C}$, is therefore a critical aspect of material design and manufacturing. To this end, computational thermodynamics provides a valuable tool in integrating experimental phase equilibrium data and predicting microstructures.

The present paper presents a study of $\mathrm{Hf}$ additions to $\mathrm{Al}_{2} \mathrm{O}_{3}$-forming $\mathrm{NiCrAl}$ alloys. Based on thermodynamic equilibrium in the alloy system, a simple criterion is devised to predict the maximum amount of $\mathrm{Hf}$ which can be added without producing $\mathrm{HfO}_{2}$ below the $\mathrm{Al}_{2} \mathrm{O}_{3}$. The applicability of such a criterion, and potential routes for improved predictability, are discussed based on experimental results obtained with $\gamma, \gamma-\gamma^{\prime}$ and $\gamma^{\prime}$ alloys at $1000-1200{ }^{\circ} \mathrm{C}\left(\gamma\right.$ and $\gamma^{\prime}$ designate the fcc A1 solid solution based on $\mathrm{Ni}$ and the ordered cubic $\mathrm{L}_{2}$ compound based on $\mathrm{Ni}_{3} \mathrm{Al}$, respectively).

\section{Experimental and computational procedures}

\subsection{Materials}

The NiCrAl-Hf alloys used for the oxidation experiments were based on four $\mathrm{NiCrAl}$ compositions, which are plotted on an isothermal section of the $\mathrm{Al}-\mathrm{Cr}-\mathrm{Ni}$ phase diagram in Fig. 1. These were chosen so as to obtain $\gamma, \gamma-\gamma^{\prime}$ and $\gamma^{\prime}$ microstructures at 1000-1200 ${ }^{\circ} \mathrm{C}$ with varying $\mathrm{Cr}$ levels, while maintaining the ability to form an $\mathrm{Al}_{2} \mathrm{O}_{3}$ scale. Nominal compositions and equilibrium phase constitutions are summarized in Tables 1 and 2, respectively. Four alloys were cast with 0.1 at. \% Hf; in two cases, 0.05 at. \% Hf additions were also used. These Hf levels were low enough to avoid the formation of Hf-containing intermetallics. A version of the $\mathrm{Ni}-8 \mathrm{Cr}-17 \mathrm{Al}-0.1 \mathrm{Hf}$ alloy was made with 0.5 at. \% Si.

The ingots were made by argon arc melting, followed by drop casting into 10$\mathrm{mm}$-diameter rods which were then homogenized in vacuum for $6 \mathrm{~h}$ at $1200{ }^{\circ} \mathrm{C}$ plus another $48 \mathrm{~h}$ at $1150{ }^{\circ} \mathrm{C}$. All processing was conducted at the Materials Preparation Center of the Ames Laboratory [20]. Compositions measured by ICP-OES (Evans Analytical Group, Liverpool, NY, USA) for selected alloys were very close to the nominal compositions, as shown in Table 1. In particular, Hf concentrations, albeit small, were controlled with satisfactory accuracy.

Specimens approximately $1 \mathrm{~mm}$ thick were vacuum-encapsulated in quartz capsules and annealed in a tube furnace at 1000,1100 and $1200{ }^{\circ} \mathrm{C}$ for 217,100 and 


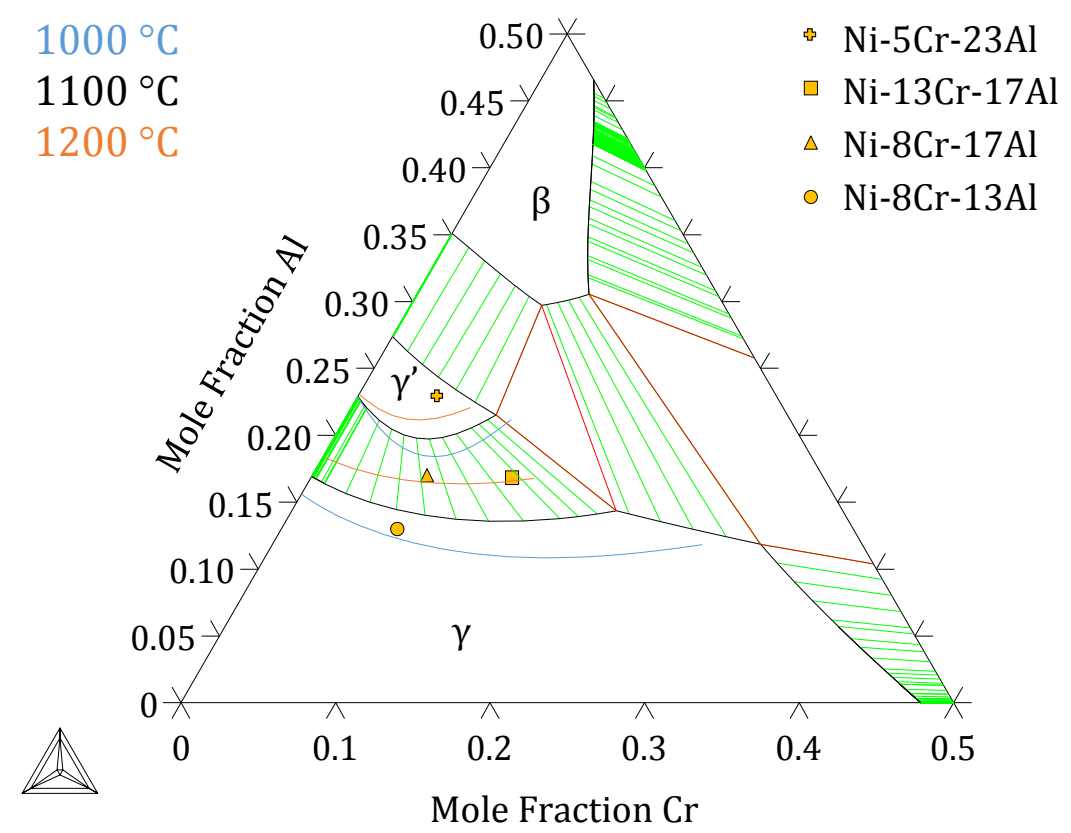

Figure 1: Isothermal section of the $\mathrm{Al}-\mathrm{Cr}-\mathrm{Ni}$ system at $1100{ }^{\circ} \mathrm{C}$, calculated from data in Ref. [19]. Portions of the $\gamma / \gamma-\gamma^{\prime}$ and $\gamma-\gamma^{\prime} / \gamma^{\prime}$ phase boundaries at 1000 and $1200{ }^{\circ} \mathrm{C}$ are superimposed, and the base $\mathrm{NiCrAl}$ alloy compositions used for oxidation experiments are indicated (color figure online).

Table 1: Nominal composition of the alloys (at. \%), balance: Ni. Included results of ICP-OES analysis of selected alloys are very close to nominal values.

\begin{tabular}{|c|c|c|c|c|c|c|c|c|}
\hline \multirow[t]{2}{*}{ Reference } & \multicolumn{4}{|c|}{ Nominal } & \multicolumn{4}{|c|}{ Measured (ICP-OES) } \\
\hline & $\mathrm{Cr}$ & $\mathrm{Al}$ & $\mathrm{Hf}$ & $\mathrm{Si}$ & $\mathrm{Cr}$ & $\mathrm{Al}$ & $\mathrm{Hf}$ & $\mathrm{Si}$ \\
\hline $\mathrm{Ni}-8 \mathrm{Cr}-13 \mathrm{Al}-0.1 \mathrm{Hf}$ & 7.5 & 13 & 0.1 & & & & & \\
\hline $\mathrm{Ni}-8 \mathrm{Cr}-17 \mathrm{Al}-0.1 \mathrm{Hf}$ & 7.5 & 16.8 & 0.1 & & 7.6 & 16.6 & 0.098 & \\
\hline $\mathrm{Ni}-8 \mathrm{Cr}-17 \mathrm{Al}-0.1 \mathrm{Hf}-0.5 \mathrm{Si}$ & 7.5 & 16.8 & 0.1 & 0.5 & 7.5 & 16.6 & 0.101 & 0.66 \\
\hline $\mathrm{Ni}-8 \mathrm{Cr}-17 \mathrm{Al}-0.05 \mathrm{Hf}$ & 7.5 & 16.8 & 0.05 & & 7.6 & 16.4 & 0.054 & \\
\hline $\mathrm{Ni}-13 \mathrm{Cr}-17 \mathrm{Al}-0.1 \mathrm{Hf}$ & 13 & 16.8 & 0.1 & & & & & \\
\hline $\mathrm{Ni}-5 \mathrm{Cr}-23 \mathrm{Al}-0.1 \mathrm{Hf}$ & 5 & 23 & 0.1 & & & & & \\
\hline $\mathrm{Ni}-5 \mathrm{Cr}-23 \mathrm{Al}-0.05 \mathrm{Hf}$ & 5 & 23 & 0.05 & & & & & \\
\hline
\end{tabular}

Table 2: Phases observed after annealing at the indicated temperatures and water quenching. Additions of Hf or Si did not modify the phase constitutions.

\begin{tabular}{lccc}
\hline & \multicolumn{3}{c}{$T\left({ }^{\circ} \mathrm{C}\right)$} \\
\cline { 2 - 4 } & 1000 & 1100 & 1200 \\
$\mathrm{Ni}-8 \mathrm{Cr}-13 \mathrm{Al}$ & $\gamma-\gamma^{\prime}$ & $\gamma$ & $\gamma$ \\
$\mathrm{Ni}-8 \mathrm{Cr}-17 \mathrm{Al}$ & $\gamma-\gamma^{\prime}$ & $\gamma-\gamma^{\prime}$ & $\gamma-\gamma^{\prime}$ \\
$\mathrm{Ni}-13 \mathrm{Cr}-17 \mathrm{Al}$ & $\gamma-\gamma^{\prime}$ & $\gamma-\gamma^{\prime}$ & $\gamma$ \\
$\mathrm{Ni}-5 \mathrm{Cr}-23 \mathrm{Al}$ & $\gamma^{\prime}$ & $\gamma^{\prime}$ & $\gamma^{\prime}$ \\
\hline
\end{tabular}



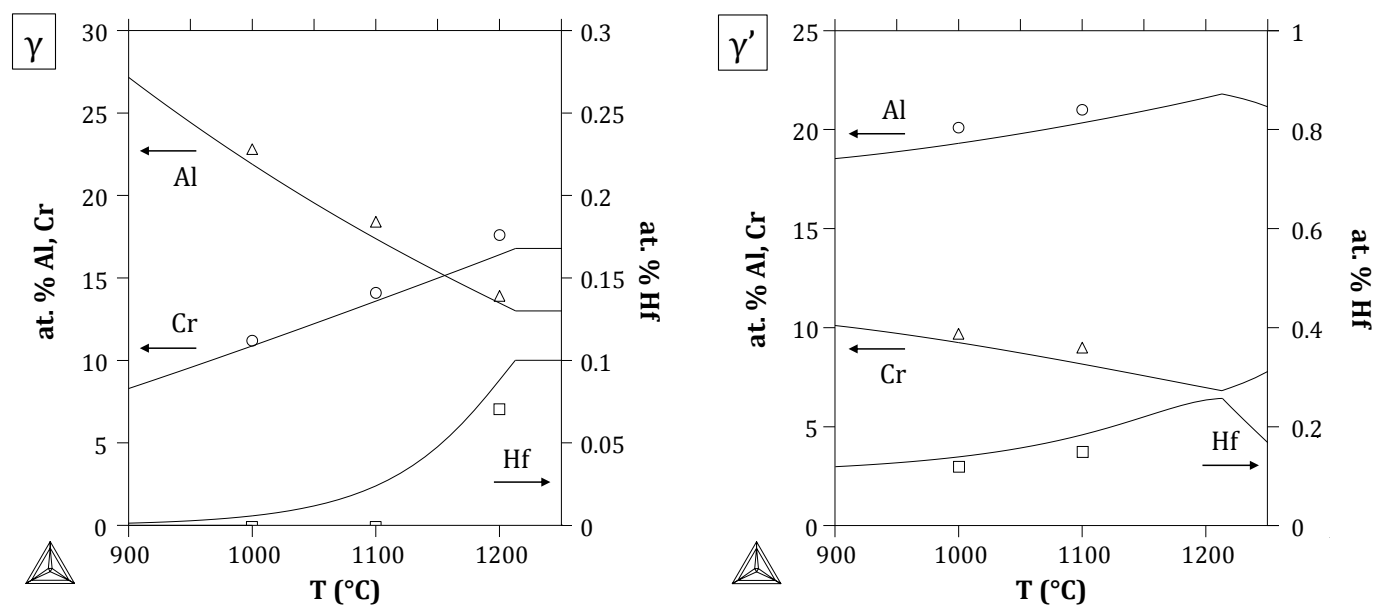

Figure 2: Calculated phase compositions of $\gamma-\gamma^{\prime}$ alloy $\mathrm{Ni}-13 \mathrm{Cr}-17 \mathrm{Al}-0.1 \mathrm{Hf}$ as a function of temperature. Compositions measured by EPMA after equilibration heat treatments (symbols) are included.

$50 \mathrm{~h}$, respectively. Based on past experience, these durations were thought to be long enough to reach thermodynamic equilibrium. The heat treatments were terminated by water quenching to retain the equilibrated microstructures.

Polished sections of the equilibrated alloys were prepared by standard metallographic procedures. Phase compositions were determined by electron probe microanalysis (EPMA) using a JEOL JXA-8530F field emission gun instrument. The measured intensities were converted to concentrations via a built-in ZAF calibration procedure using pure metals as standards. The $\gamma$ and $\gamma^{\prime}$ compositions were found to be in good agreement with equilibrium values calculated from Dupin et al.'s $\mathrm{Al}-\mathrm{Cr}-\mathrm{Ni}$ assessment [19]. Plots of measured versus calculated concentrations are given in Fig. 2 for $\mathrm{Ni}-13 \mathrm{Cr}-17 \mathrm{Al}-0.1 \mathrm{Hf}$. In $\gamma-\gamma^{\prime}$ alloys, the Hf solubility in $\gamma$ was too small to be accurately measured; however, the Hf concentration measured in $\gamma^{\prime}$ was in good agreement with the Hf solubility calculated using our developmental $\mathrm{Al}-\mathrm{Cr}-\mathrm{Hf}-\mathrm{Ni}$ database (see modeling section below).

\subsection{Oxidation experiments}

Oxidation experiments were conducted at 1000,1100 and $1200{ }^{\circ} \mathrm{C}$ using specimens equilibrated at the same temperatures. Approximately $100 \mu \mathrm{m}$ of material was ground off the specimen surfaces using $\mathrm{SiC}$ paper so as to remove any layer affected by oxidation or sublimation during the equilibration treatment. The specimens were then ground down to a P1200-grit finish, degreased with detergent and ultrasonically cleaned in ethanol. This procedure was used to have well-defined, equilibrium microstructures at the alloy surfaces from the beginning of the oxidation process.

The oxidation experiments were carried out in flowing dry air using a horizontal tube furnace. Gas flow rates were set to $100 \mathrm{ml} / \mathrm{min}$ (about $2 \mathrm{~mm} / \mathrm{s}$ in the hot zone), with a pressure slightly over $1 \mathrm{~atm}$. Prior to a given experiment, the furnace was stabilized at the desired temperature with the specimens positioned in a cold zone of the reaction tube, and the gas allowed to flow for $2 \mathrm{~h}$. To start the experiment, the specimens were magnetically pushed in the hot zone. All alloys were oxidized 
$20 \mathrm{~h}$ at the three temperatures; shorter exposures were done in selected cases. After exposure, polished sections of the reacted alloys were examined by SEM (JEOL JSM 6510) and by EPMA in some cases.

\subsection{Thermodynamic modeling}

The Al-Cr-Hf-Ni system was modeled using the CALPHAD (CALculation of PHase Diagrams) method [21], where multicomponent sublattice models based on the compound energy formalism were used to describe the Gibbs free energy of the solid solution phases. Details of the modeling procedure will be described in separate publications. Briefly, the description of the $\mathrm{Al}-\mathrm{Cr}-\mathrm{Ni}$ system by Dupin et al. [19] was adopted and combined with that of the most relevant Hf-containing binary and ternary systems. The Hf-Ni system was remodeled based on the work by Wang et al. [22] with new experimental data (EPMA, DSC) and finite-temperature firstprinciples data (Debye, SQS) obtained by density functional theory. The Al-Hf-Ni and $\mathrm{Cr}-\mathrm{Hf}-\mathrm{Ni}$ systems were modeled by considering the ternary compounds as well as the $\mathrm{Al}$ and $\mathrm{Cr}$ solubility in the $\mathrm{Hf}_{2} \mathrm{Ni}_{7}$ phase.

The ability of NiCrAl-Hf alloys to maintain $\mathrm{Hf}$ in solution and hence limit the formation of pegs was determined by considering a simple variable, the Hf concentration required to form $\mathrm{HfO}_{2}$ at the $\mathrm{O}$ activity defined by the alloy $/ \mathrm{Al}_{2} \mathrm{O}_{3}$ equilibrium (i.e., below a thermally growing $\mathrm{Al}_{2} \mathrm{O}_{3}$ scale at steady-state). $\mathrm{HfO}_{2}$ is more stable than $\mathrm{Al}_{2} \mathrm{O}_{3}$ at unit activity of the respective metals; yet for a sufficiently low $\mathrm{Hf}$ activity in an alloy, $\mathrm{HfO}_{2}$ will not be stable at the reduced $p_{\mathrm{O}_{2}}$ prevailing below the $\mathrm{Al}_{2} \mathrm{O}_{3}$. This threshold activity is related to the energy of mixing of $\mathrm{Hf}$, which also determines its solubility in a given alloy phase. Since Hf is more soluble in $\gamma^{\prime}$ than in $\gamma$ (Fig. 2), at a given Hf activity, the Hf concentration is larger in $\gamma^{\prime}$. Thus, the $\mathrm{Hf}$ concentration for $\mathrm{HfO}_{2}$ formation, or $\mathrm{Hf}$ tolerance, is predicted to be larger in $\gamma^{\prime}$ than in $\gamma$ (or in $\beta$, which dissolves very little $\mathrm{Hf}$ ). Plots of the Hf tolerance as a function of $\mathrm{Cr}$ and $\mathrm{Al}$ concentrations at $1000-1200{ }^{\circ} \mathrm{C}$ are given in Fig. 3. All calculations were made using Thermo-Calc [23, 24].

Figure 3 shows that the Hf tolerance is affected both by phase changes and by composition changes within a given phase field. Within $\gamma$ or $\beta$, increasing the $\mathrm{Al}$ content causes a slight increase in Hf tolerance, while $\mathrm{Cr}$ variations have little effect. In $\gamma^{\prime}$, however, the effects of $\mathrm{Al}$ and $\mathrm{Cr}$ variations are non-monotonic and can be large. Increasing $\mathrm{Al}$ generally causes the $\mathrm{Hf}$ tolerance to increase, especially at low $\mathrm{Cr}$ levels. The effect is limited and locally opposite at higher $\mathrm{Cr}$ levels, near the $\gamma-$ $\gamma^{\prime}-\beta$ triangle. Conversely, increasing $\mathrm{Cr}$ leads to a decrease in Hf tolerance, except at low $\mathrm{Cr}$ levels where an opposite effect is observed. These variations reflect the complex interplay between phase equilibria in the metal system and in the alloy$\mathrm{HfO}_{2}-\mathrm{Al}_{2} \mathrm{O}_{3}$ pseudo-ternary system: $\mathrm{Al}$ and $\mathrm{Cr}$ concentrations determine $\mathrm{Al}$ and $\mathrm{Cr}$ activities via activity coefficients in the $\mathrm{Al}-\mathrm{Cr}-\mathrm{Ni}$ ternary; the $\mathrm{Al}$ activity defines an equilibrium $p_{\mathrm{O}_{2}}$ at the alloy $/ \mathrm{Al}_{2} \mathrm{O}_{3}$ interface, which in turn yields an $\mathrm{Hf}$ activity for $\mathrm{HfO}_{2}$ formation; finally, the threshold $\mathrm{Hf}$ concentration (Hf tolerance) depends on both this equilibrium $\mathrm{Hf}$ activity and the $\mathrm{Al}$ and $\mathrm{Cr}$ concentrations, via the topology of the quaternary Al-Cr-Hf-Ni system. 

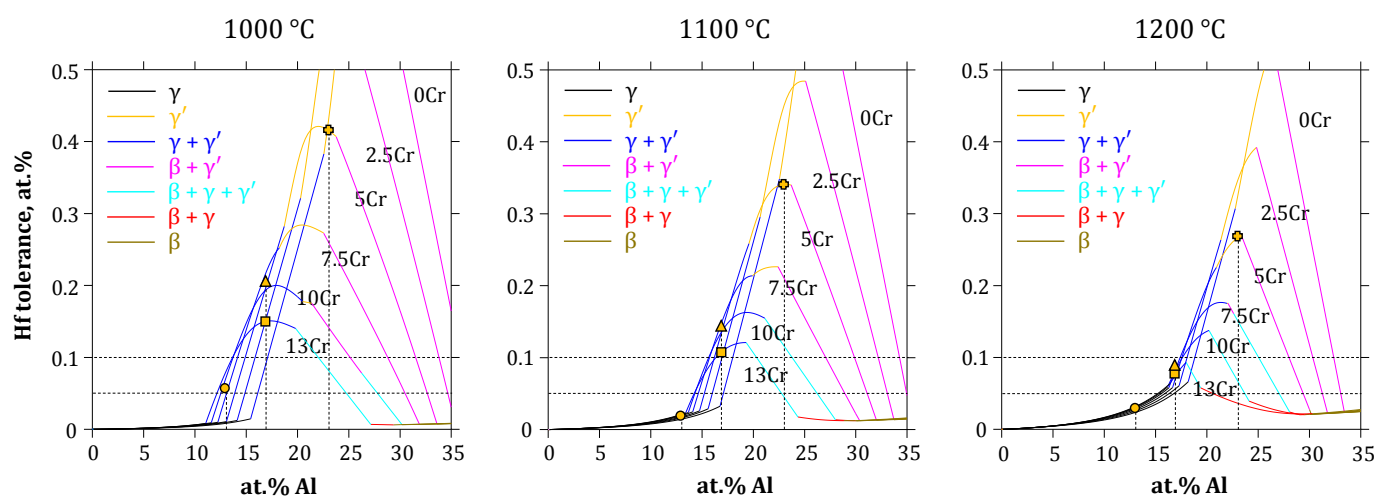

Figure 3: Calculated $\mathrm{Hf}$ concentration required to form $\mathrm{HfO}_{2}$ at the $\mathrm{O}$ activity defined by the alloy $/ \mathrm{Al}_{2} \mathrm{O}_{3}$ equilibrium, i.e., below a growing $\mathrm{Al}_{2} \mathrm{O}_{3}$ scale, as a function of $\mathrm{Al}$ concentration, at varying Cr levels. This "Hf tolerance" is the maximum Hf concentration which can be included in an alloy to avoid $\mathrm{HfO}_{2}$ formation, based on the equilibrium alloy phase compositions. The yellow symbols represent the base $\mathrm{NiCrAl}$ compositions used for oxidation experiments (see Fig. 1) (color figure online).

\section{Results and discussion}

\subsection{General observations}

Cross-sections of the NiCrAl-0.1Hf alloys after 20-h oxidation at 1000, 1100 and $1200{ }^{\circ} \mathrm{C}$ are shown in Fig. 4. The $\mathrm{Ni}-8 \mathrm{Cr}-13 \mathrm{Al}-0.1 \mathrm{Hf}$ alloy was a marginal $\mathrm{Al}_{2} \mathrm{O}_{3}-$ former at 1000 and $1100{ }^{\circ} \mathrm{C}$, in that it locally formed nodules of $\mathrm{NiO}$ and mixed $\mathrm{Ni}-\mathrm{Cr}-\mathrm{Al}$ oxide in addition to $\mathrm{Al}_{2} \mathrm{O}_{3}$ at these temperatures. Similarly, the $\mathrm{Ni}-$ $5 \mathrm{Cr}-23 \mathrm{Al}-0.1 / 0.05 \mathrm{Hf}$ alloys locally formed mixed oxide scales with internal $\mathrm{Al}_{2} \mathrm{O}_{3}$ at 1000 and $1100{ }^{\circ} \mathrm{C}$. The other alloys produced thin $\mathrm{Al}_{2} \mathrm{O}_{3}$ scales at all three temperatures. Particles of a Hf-rich oxide, referred to as $\mathrm{HfO}_{2}$ hereafter, formed in varying quantities within or below the $\mathrm{Al}_{2} \mathrm{O}_{3}$. In order to assess the results of the thermodynamic calculation, the alloys were divided into three categories, based on whether $\mathrm{HfO}_{2}$ particles were (1) not observed (see for example Ni-5Cr-23Al-0.1Hf at $1200{ }^{\circ} \mathrm{C}$ in Fig. 4), (2) observed locally (see $\mathrm{Ni}-8 \mathrm{Cr}-17 \mathrm{Al}-0.1 \mathrm{Hf}$ at $1100{ }^{\circ} \mathrm{C}$ ) or (3) observed consistently (see $\mathrm{Ni}-13 \mathrm{Cr}-17 \mathrm{Al}-0.1 \mathrm{Hf}$ at $1200{ }^{\circ} \mathrm{C}$ ).

Due to the discrete nature of the $\mathrm{HfO}_{2}$ particles, their varying size and volume fraction, the outcome of any classification necessarily depends on the methods used. Here, Hf oxidation was deemed localized when micron-scale $\mathrm{HfO}_{2}$ particles were spaced by more than $\sim 5 \mu \mathrm{m}$ apart along the $\mathrm{Al}_{2} \mathrm{O}_{3}$ scale, as observed by SEM. Smaller $(\sim 50 \mathrm{~nm})$, isolated $\mathrm{HfO}_{2}$ particles were observed at high magnification, including in the case of alloys classified as "no $\mathrm{HfO}_{2}$," and it is recognized that particles too small to be detected by SEM likely also existed. These submicron $\mathrm{HfO}_{2}$ particles are believed to form, in part, in the transient initial stage of the oxidation process. Increasing the oxidation temperature generally accelerates the establishment of a continuous $\alpha-\mathrm{Al}_{2} \mathrm{O}_{3}$ scale and limits the formation of transient oxides, i.e., $\theta-\mathrm{Al}_{2} \mathrm{O}_{3}$ and oxides of $\mathrm{Ni}$ and $\mathrm{Cr}$. Indeed, from 1000 to $1200{ }^{\circ} \mathrm{C}$, the amount of submicron $\mathrm{HfO}_{2}$ particles decreased (see Ni-5Cr-23Al-0.1Hf in Fig. 4), despite a predicted rise in the driving force for Hf oxidation. 


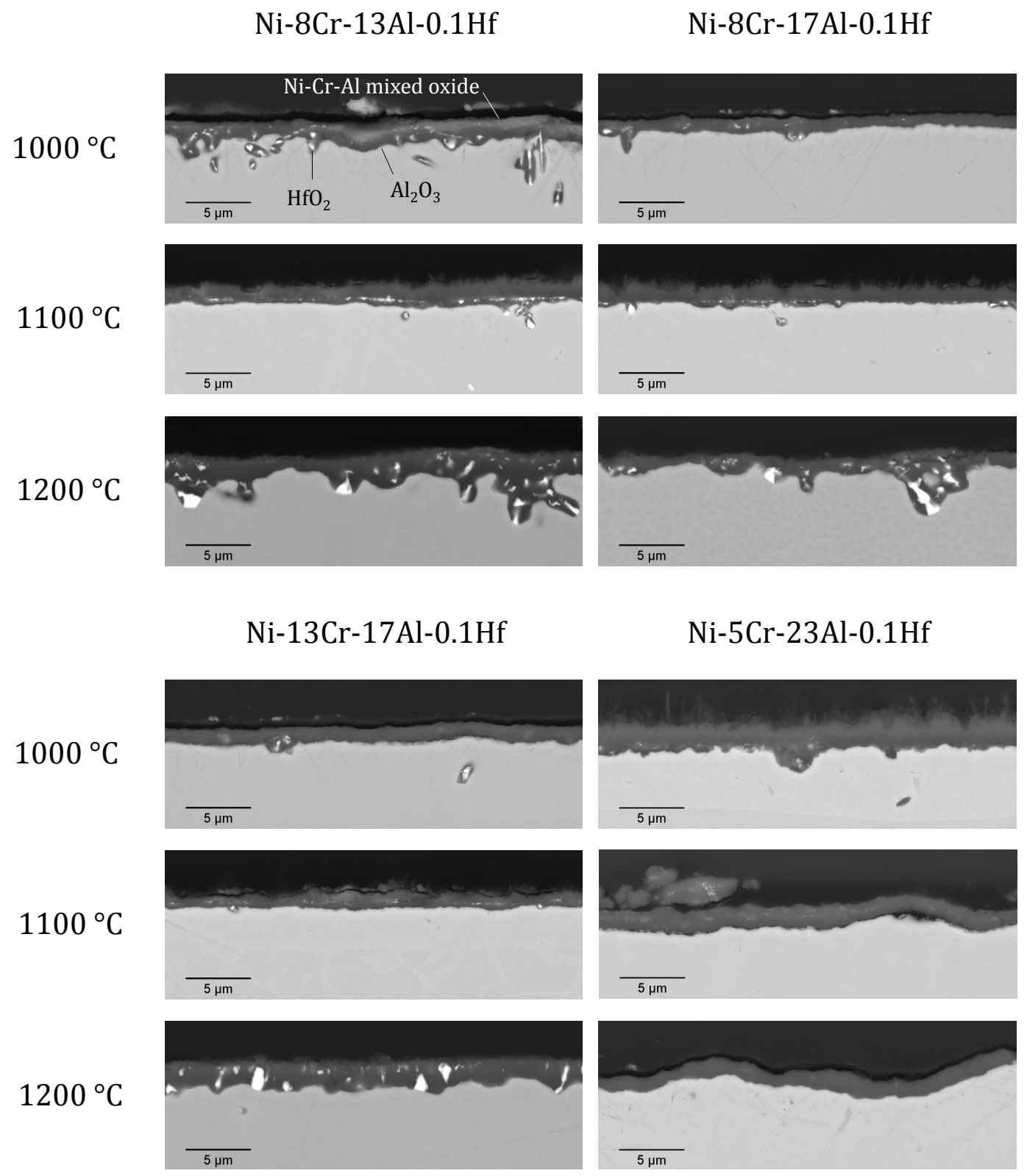

Figure 4: Cross-sections of the Ni-8Cr-13Al-0.1Hf, Ni-8Cr-17Al-0.1Hf, Ni-13Cr-17Al$0.1 \mathrm{Hf}$ and $\mathrm{Ni}-5 \mathrm{Cr}-23 \mathrm{Al}-0.1 \mathrm{Hf}$ alloys oxidized $20 \mathrm{~h}$ at 1000,1100 and $1200{ }^{\circ} \mathrm{C}$. The bright particles visible within or below the $\mathrm{Al}_{2} \mathrm{O}_{3}$ scales consist of Hf-rich oxide, referred to as $\mathrm{HfO}_{2}$. 


\begin{tabular}{|c|c|c|c|c|c|c|c|}
\hline & \multicolumn{3}{|c|}{ Prediction } & \multicolumn{3}{|c|}{ Observation } & \\
\hline & \multicolumn{3}{|c|}{$\mathrm{T}\left({ }^{\circ} \mathrm{C}\right)$} & \multicolumn{3}{|c|}{$\mathrm{T}\left({ }^{\circ} \mathrm{C}\right)$} & \\
\hline & 1000 & 1100 & 1200 & 1000 & 1100 & 1200 & \\
\hline $\mathrm{Ni}-8 \mathrm{Cr}-13 \mathrm{Al}-0.1 \mathrm{Hf}$ & yes & yes & yes & yes & yes & yes & \\
\hline Ni-8Cr-17Al-0.1Hf & no & no & yes & loc & loc & yes & \\
\hline $\mathrm{Ni}-8 \mathrm{Cr}-17 \mathrm{Al}-0.05 \mathrm{Hf}$ & no & no & no & loc & loc & loc & Agreement \\
\hline $\mathrm{Ni}-13 \mathrm{Cr}-17 \mathrm{Al}-0.1 \mathrm{Hf}$ & no & no & yes & loc & yes & yes & Disagreement \\
\hline $\mathrm{Ni}-5 \mathrm{Cr}-23 \mathrm{Al}-0.1 \mathrm{Hf}$ & no & no & no & loc & loc & no & \\
\hline $\mathrm{Ni}-5 \mathrm{Cr}-23 \mathrm{Al}-0.05 \mathrm{Hf}$ & no & no & no & no & no & no & \\
\hline
\end{tabular}

Figure 5: Summary of predicted formation of $\mathrm{HfO}_{2}$ below an $\mathrm{Al}_{2} \mathrm{O}_{3}$ scale based on calculation shown in Fig. 3, compared with experimental observations after 20-h oxidation of equilibrated alloys. Experimental results were divided into three categories, based on whether $\mathrm{HfO}_{2}$ particles were not observed (="no"), observed locally (= "loc") or observed consistently (="yes"). See details in text (color figure online).

\subsection{Factors affecting Hf tolerance}

The observed presence or absence of $\mathrm{HfO}_{2}$ is compared in Fig. 5, for each alloy and temperature, with the prediction based on the Hf tolerance plots (Fig. 3). In general, the prediction was rather good, in that whenever $\mathrm{Hf}$ was predicted to oxidize, $\mathrm{HfO}_{2}$ was indeed observed, and when $\mathrm{Hf}$ was predicted not to oxidize, $\mathrm{HfO}_{2}$ was either not observed or observed locally. Factors affecting the Hf tolerance are now addressed individually.

$\gamma / \gamma^{\prime}$ phase fractions. The experimental results followed the trend expected from the equilibrium calculation, i.e., alloys with a larger $\gamma^{\prime}$ fraction tended to form less $\mathrm{HfO}_{2}$, due to the larger solubility of $\mathrm{Hf}$ in $\gamma^{\prime}$ (compare $\mathrm{Ni}-8 \mathrm{Cr}-13 \mathrm{Al}-0.1 \mathrm{Hf}$ with $\mathrm{Ni}-8 \mathrm{Cr}-17 \mathrm{Al}-0.1 \mathrm{Hf}$ and $\mathrm{Ni}-5 \mathrm{Cr}-23 \mathrm{Al}-0.1 \mathrm{Hf}$, and $\mathrm{Ni}-8 \mathrm{Cr}-17 \mathrm{Al}-0.05 \mathrm{Hf}$ with $\mathrm{Ni}-5 \mathrm{Cr}-23 \mathrm{Al}-0.05 \mathrm{Hf})$.

Cr concentration. The Hf tolerance is predicted to slightly decrease with increasing $\mathrm{Cr}$ in $\mathrm{Ni}-\mathrm{Cr}-17 \mathrm{Al}$ alloys. This was verified to some extent, as larger amounts of $\mathrm{HfO}_{2}$ formed in $\mathrm{Ni}-13 \mathrm{Cr}-17 \mathrm{Al}-0.1 \mathrm{Hf}$ than in $\mathrm{Ni}-8 \mathrm{Cr}-17 \mathrm{Al}-0.1 \mathrm{Hf}$; however, no significant difference between the two alloys was observed at 1000 or $1200{ }^{\circ} \mathrm{C}$. Other factors affecting Hf oxidation in these alloys are discussed subsequently. It is noted that a much sharper decrease in Hf tolerance with increasing $\mathrm{Cr}$ concentration is predicted to occur at high $\mathrm{Al}$ and low $\mathrm{Cr}$ concentrations, within the single-phase $\gamma^{\prime}$ field and into the $\gamma^{\prime}-\beta$ field. This region of the phase diagram was not explored experimentally.

Si concentration. Although $\mathrm{Si}$ is not included in the thermodynamic modeling at present, previous experimental results [25] indicated that 0.5-1.0 at. \% Si additions to Hf-Y co-doped $\gamma-\gamma^{\prime}$ alloys reduced Hf oxidation, suggesting that $\mathrm{Si}$ lowered the $\mathrm{Hf}$ activity. At variance with those results, it was found in the present study that adding 0.5 at. \% $\mathrm{Si}$ to $\mathrm{Ni}-8 \mathrm{Cr}-17 \mathrm{Al}-0.1 \mathrm{Hf}$ had no significant effect. Further investigation of the role of $\mathrm{Si}$ is in progress. 
Temperature. For a given alloy, the Hf tolerance is expected to decrease with increasing temperature, and indeed, the extent of Hf oxidation in $\gamma-\gamma^{\prime}$ alloys $\mathrm{Ni}-8 \mathrm{Cr}-17 \mathrm{Al}-0.1 \mathrm{Hf}$ and $\mathrm{Ni}-13 \mathrm{Cr}-17 \mathrm{Al}-0.1 \mathrm{Hf}$ increased from 1000 to $1200{ }^{\circ} \mathrm{C}$. This is consistent with the simultaneous decrease in $\gamma^{\prime}$ fraction in this temperature range. Although this trend is also expected within the single-phase $\gamma^{\prime}$ field, the $\mathrm{Ni}-5 \mathrm{Cr}-23 \mathrm{Al}-0.1 \mathrm{Hf}$ alloy formed less $\mathrm{HfO}_{2}$ as the temperature increased. As discussed earlier, this is inferred to be due to the faster establishment of $\mathrm{Al}_{2} \mathrm{O}_{3}$ and reduced transient oxidation at higher temperatures, a factor which is independent from the thermodynamic considerations involved in the Hf tolerance calculation.

\subsection{Role of subsurface compositional changes due to oxidation}

The equilibrium calculation failed to predict the local $\mathrm{HfO}_{2}$ formation observed in the $\gamma-\gamma^{\prime}$ alloys. In examining this discrepancy, we note that while the Hf tolerance is calculated based on equilibrium phase compositions, i.e., on the composition of the alloy surfaces prior to oxidation, the composition of an alloy at the metal/oxide interface changes as oxidation proceeds, due to selective $\mathrm{Al}$ removal to form $\mathrm{Al}_{2} \mathrm{O}_{3}$ (if scale growth is parabolic, a constant interfacial composition is reached at steady state [26-29]). An obvious manifestation of this change is the dissolution of $\gamma^{\prime}$ below the scale.

Composition profiles measured by EPMA in the $\mathrm{Ni}-8 \mathrm{Cr}-13 \mathrm{Al}-0.1 \mathrm{Hf}, \mathrm{Ni}-8 \mathrm{Cr}-$ $17 \mathrm{Al}-0.1 \mathrm{Hf}$ and $\mathrm{Ni}-13 \mathrm{Cr}-17 \mathrm{Al}-0.1 \mathrm{Hf}$ alloys after oxidation at $1100{ }^{\circ} \mathrm{C}$ are shown in Fig. 6. In the case of $\mathrm{Ni}-8 \mathrm{Cr}-17 \mathrm{Al}-0.1 \mathrm{Hf}$, the interfacial concentrations of $\mathrm{Cr}$ and $\mathrm{Al}$ are measured to be $\sim 9$ and 11 at. \%, respectively. If these values are used instead of the bulk concentrations, Fig. 3 predicts an Hf tolerance of about 0.01 at. \%, well below 0.1 at. \%. Qualitatively, this is consistent with the observed Hf oxidation in this alloy. Yet the Hf tolerance obtained this way is probably underestimated, since Hf oxidation was only local. Furthermore, a detailed analysis of depletion kinetics during the initial stage of selective oxidation shows that the interfacial alloy composition goes through a minimum before attaining the steady-state value [27,29]. Taking this minimum into account would lead to an even larger underestimation of the Hf tolerance.

It may be argued that by the time the metal/oxide interface reaches its steadystate composition, much of the Hf initially present in the subsurface could be consumed to form $\mathrm{HfO}_{2}$, and $\mathrm{Al}$ depletion is of little importance. Indeed, is Hf oxidation governed by transient processes, or does the scale equilibrate with the underlying alloy at steady-state? A related question concerns the influence of Hf segregation on the local Hf concentration at the alloy surface in the early stage of oxidation. Elucidation of these questions would require a quantitative mass balance on $\mathrm{Hf}$ in the scale and the alloy after varying reaction times, which would be challenging in practice given the small size of $\mathrm{HfO}_{2}$ precipitates in the scale and the low $\mathrm{Hf}$ solubility in the alloy $\gamma$ phase. In considering the relative importance of transient oxidation, we note that cases of localized Hf oxidation were observed for the $\gamma-\gamma^{\prime}$ alloys $\mathrm{Ni}-8 \mathrm{Cr}-17 \mathrm{Al}-0.1 \mathrm{Hf}$ and $\mathrm{Ni}-13 \mathrm{Cr}-17 \mathrm{Al}-0.1 \mathrm{Hf}$. The question of whether local Hf oxidation in the early stage is related to the initial two-phase alloy microstructure is examined next. 

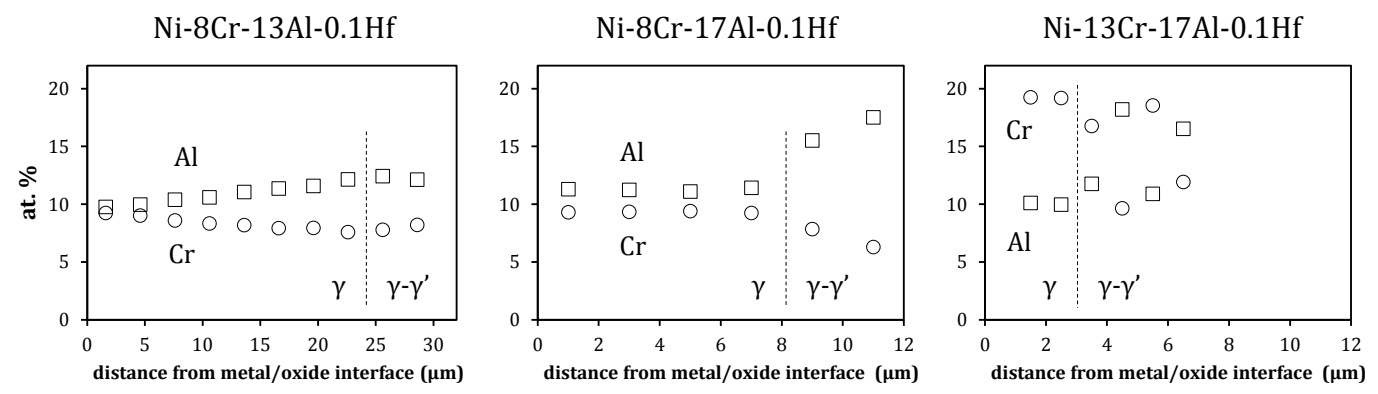

Figure 6: Composition profiles measured by EPMA below $\mathrm{Al}_{2} \mathrm{O}_{3}$ scales after 20-h oxidation at $1100{ }^{\circ} \mathrm{C}$. For each alloy, two profiles were recorded at random locations, and found to be consistent; only one is showed for clarity. In the case of $\mathrm{Ni}-8 \mathrm{Cr}-13 \mathrm{Al}-0.1 \mathrm{Hf}$, the $\gamma^{\prime}$ present in the bulk precipitated during air cooling at the end of the oxidation test. No $\gamma^{\prime}$ was observed when the alloy was water-quenched. Interdiffusion work in Ref. [30] showed that both $\tilde{D}_{\mathrm{Al}, \mathrm{Al}}^{\mathrm{Ni}}$ and $\tilde{D}_{\mathrm{Al}, \mathrm{Cr}}^{\mathrm{Ni}}$ varied significantly with $\mathrm{Al}$ concentration but not with $\mathrm{Cr}$. These thermodynamic interactions and the relative values of the main and cross terms explain why the $\mathrm{Al}$ depletion profiles measured here were flat for both $\mathrm{Ni}-8 \mathrm{Cr}-17 \mathrm{Al}-0.1 \mathrm{Hf}$ and $\mathrm{Ni}-13 \mathrm{Cr}-17 \mathrm{Al}-0.1 \mathrm{Hf}$, but not for $\mathrm{Ni}-8 \mathrm{Cr}-13 \mathrm{Al}-0.1 \mathrm{Hf}$.

\subsection{Early stage oxidation processes}

Short-term, 3-min oxidation tests were conducted on the $\gamma-\gamma^{\prime}$ alloys $\mathrm{Ni}-8 \mathrm{Cr}-17 \mathrm{Al}-$ $0.1 \mathrm{Hf}$ and $\mathrm{Ni}-13 \mathrm{Cr}-17 \mathrm{Al}-0.1 \mathrm{Hf}$ at $1100{ }^{\circ} \mathrm{C}$. Based on past experience, it takes about two minutes for the specimens to heat to $1100{ }^{\circ} \mathrm{C}$ after being pushed in the hot zone in these experimental conditions. Thus, the 3 -min exposure was mostly anisothermal, with only about a minute at $1100{ }^{\circ} \mathrm{C}$.

After short-term exposure, a thin $\mathrm{Al}_{2} \mathrm{O}_{3}$ scale had formed, $\gamma^{\prime}$ had started to dissolve, and $\mathrm{HfO}_{2}$ particles were observed within the $\mathrm{Al}_{2} \mathrm{O}_{3}$ and at the metal/oxide interface (Fig. 7). The scale and subscale regions were analyzed by EPMA; an example of X-ray maps obtained from $\mathrm{Ni}-13 \mathrm{Cr}-17 \mathrm{Al}-0.1 \mathrm{Hf}$ is given in Fig. 8. In the $\mathrm{Al}$ map, a band of $\gamma^{\prime}$-free material (i.e., a $\gamma$-band) is seen below the scale, which is also visible in the back-scattered image. Remarkably, the $\mathrm{Cr}$ concentration is not evenly distributed in this $\gamma$-band: it is lower in regions located directly above $\gamma^{\prime}$ and higher above $\gamma$. Point analysis confirmed that concentrations in the $\gamma$-band were all between the bulk $\gamma$ and $\gamma^{\prime}$ values, but with differences of up to 3 at. \% depending on whether the phase located directly below was $\gamma$ or $\gamma^{\prime}$. A similar trend was observed for the Hf level, which was slightly higher above $\gamma^{\prime}$ than above $\gamma$.

Chemical and microstructural analysis of the subscale region suggests that following $\mathrm{Al}$ removal and $\gamma^{\prime}$ dissolution, $\mathrm{Cr}$ and $\mathrm{Hf}$ diffusion was not fast enough to remove the original $\gamma-\gamma^{\prime}$ partitioning, which resulted in a local $\mathrm{Cr}$ undersaturation and Hf supersaturation in the newly formed $\gamma$. Thus, in the first minutes of exposure, the $\gamma$-band was in a state of non-equilibrium with respect to $\mathrm{Cr}$ and $\mathrm{Hf}$, resulting in local variations of the Hf activity $\left(a_{\mathrm{Hf}}\right)$ across the prior $-\gamma / \gamma^{\prime}$ assemblage. In particular, because of the difference of Hf solubility between $\gamma$ and $\gamma^{\prime}$, the phase change involved a rise of $a_{\mathrm{Hf}}$ in prior- $\gamma^{\prime}$ regions. This is represented in Fig. 9, where $a_{\mathrm{Hf}}$ in the non-equilibrium $\gamma$-band was obtained by suspending $\gamma^{\prime}$ in the equilibrium calculation. For each region of the $\gamma$-band, $\gamma^{\prime}$ dissolution is seen to cause both an increase in $a_{\mathrm{Hf}}$ and a decrease in the $a_{\mathrm{Hf}}$ required to form $\mathrm{HfO}_{2}$ at the 


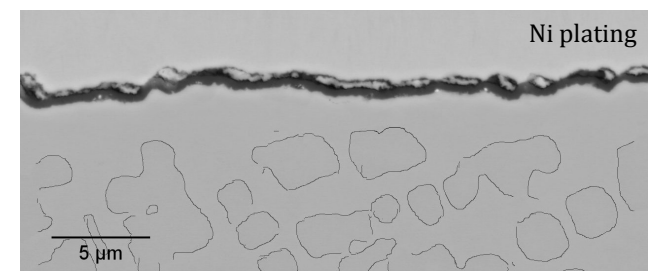

(a) Ni-8Cr-17Al-0.1Hf

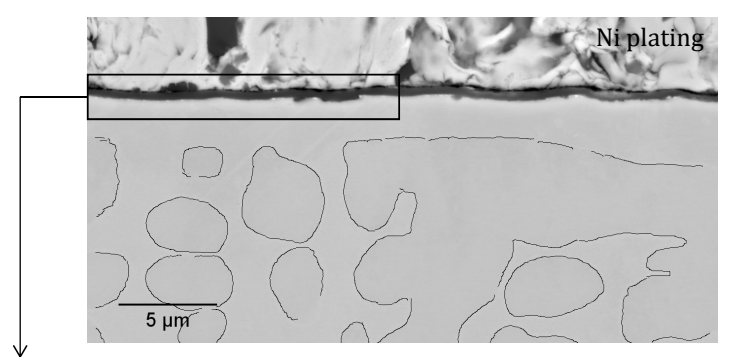

(b) $\mathrm{Ni}-13 \mathrm{Cr}-17 \mathrm{Al}-0.1 \mathrm{Hf}$

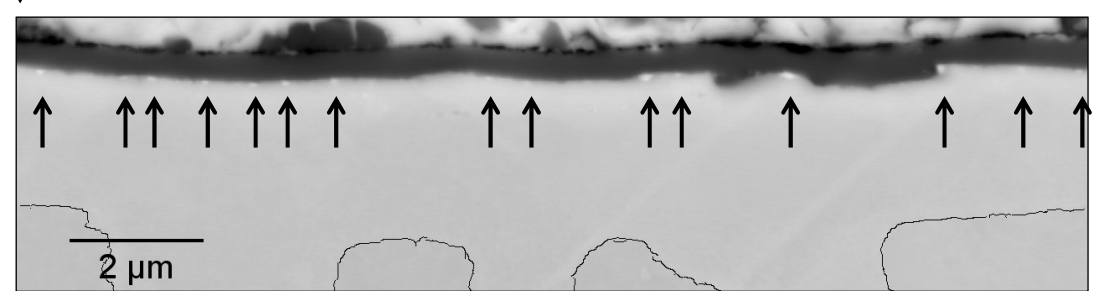

Figure 7: Cross-sections of the (a) Ni-8Cr-17Al-0.1Hf and (b) Ni-13Cr-17Al-0.1Hf alloys oxidized $3 \mathrm{~min}$ at $1100{ }^{\circ} \mathrm{C}$. An automatic edge detection routine was used to outline the $\gamma / \gamma^{\prime}$ phase boundaries. In (b) a zoomed view of the $\mathrm{Al}_{2} \mathrm{O}_{3}$ scale is shown, with arrows pointing to the location of $\mathrm{HfO}_{2}$ precipitates.

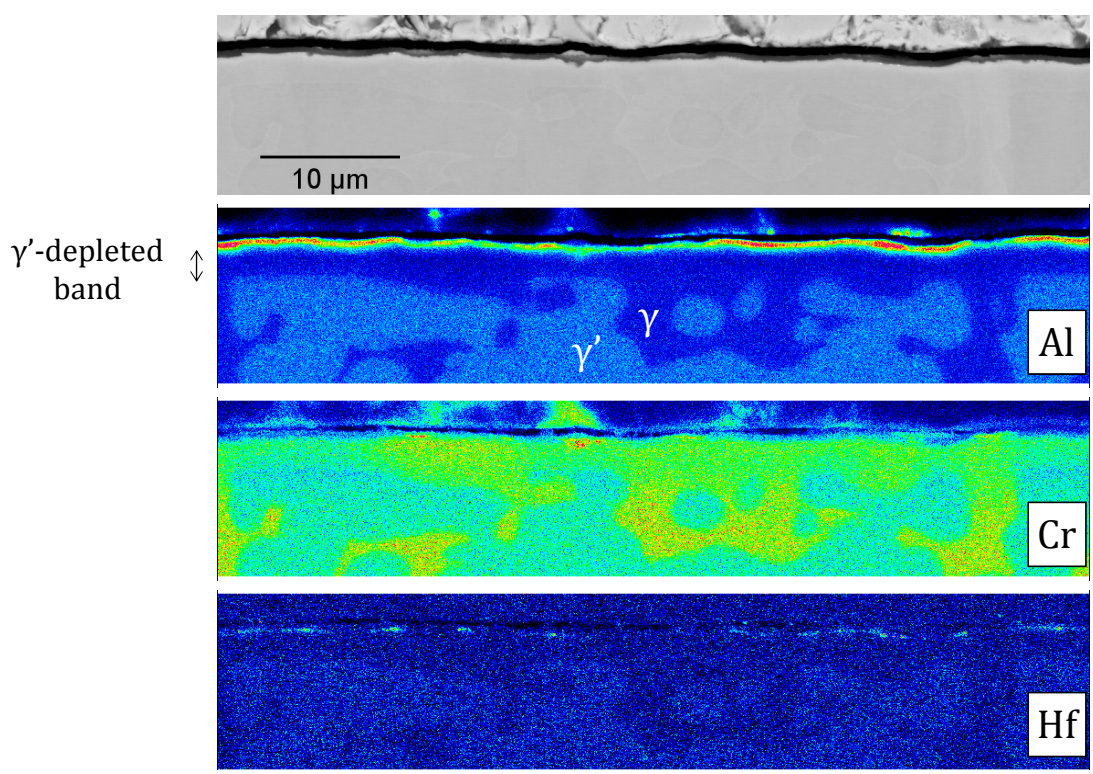

Figure 8: Back-scattered image and corresponding $\mathrm{Al}, \mathrm{Cr}$ and $\mathrm{Hf} \mathrm{X}$-ray maps recorded by EPMA after 3-min oxidation of alloy $\mathrm{Ni}-13 \mathrm{Cr}-17 \mathrm{Al}-0.1 \mathrm{Hf}$ at $1100{ }^{\circ} \mathrm{C}$. The $\mathrm{Cr}$ concentration is non-uniform in the $\gamma^{\prime}$-depleted band (color figure online). 


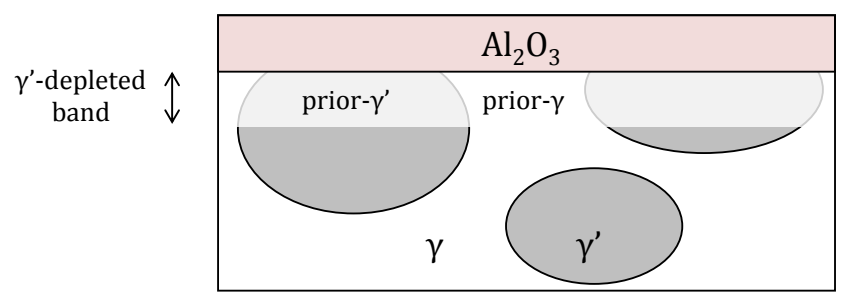

\begin{tabular}{|c|c|c|c|c|c|c|}
\hline \multirow[b]{2}{*}{ Phase $\varphi$} & \multicolumn{4}{|c|}{ Definition } & \multicolumn{2}{|c|}{ Hf activity at $1100^{\circ} \mathrm{C}$} \\
\hline & $\begin{array}{c}x_{\mathrm{Al}} \\
\text { EPMA, at. \% }\end{array}$ & $x_{\mathrm{Cr}}$ & $x_{\mathrm{Hf}}$ & $\gamma^{\prime}$ & in phase $\varphi$ & $\begin{array}{c}\text { at } \varphi-\mathrm{HfO}_{2}-\mathrm{Al}_{2} \mathrm{O}_{3} \\
\text { equilibrium }\end{array}$ \\
\hline original $\gamma$ & 14 & $\left(x_{\mathrm{Cr}}^{\gamma}\right)_{\mathrm{eq}}$ & $\left(x_{\mathrm{Hf}}^{\gamma}\right)_{\mathrm{eq}}$ & included & $4.2 \cdot 10^{-11}$ & $4.6 \cdot 10^{-11}$ \\
\hline prior- $\gamma$ & 11 & $\left(x_{\mathrm{Cr}}^{\gamma}\right)_{\mathrm{eq}}$ & $\left(x_{\mathrm{Hf}}^{\gamma}\right)_{\mathrm{eq}}$ & suspended & $3.0 \cdot 10^{-11}$ & $1.8 \cdot 10^{-11}$ \\
\hline prior- $\gamma^{\prime}$ & 13 & $\left(x_{\mathrm{Cr}}^{\gamma^{\prime}}\right)_{\mathrm{eq}}$ & $\left(x_{\mathrm{Hf}}^{\gamma^{\prime}}\right)_{\mathrm{eq}}$ & suspended & $9.1 \cdot 10^{-11}$ & $9.1 \cdot 10^{-12}$ \\
\hline
\end{tabular}

Figure 9: Hf activity changes induced by selective oxidation of $\mathrm{Ni}-13 \mathrm{Cr}-17 \mathrm{Al}-0.1 \mathrm{Hf}$ at $1100{ }^{\circ} \mathrm{C}$. After 3 -min exposure, the $\gamma^{\prime}$-depleted band is in a non-equilibrium state, with partial retention of the original $\mathrm{Cr}$ and $\mathrm{Hf}$ partitioning, because of the slow diffusion of these elements, relative to Al. The non-equilibrium regions were modeled by suspending $\gamma^{\prime}$ and setting the $\mathrm{Cr}$ and $\mathrm{Hf}$ concentrations to those of the original $\gamma$ and $\gamma^{\prime}$, while using experimentally measured $\mathrm{Al}$ concentrations. For each phase, the calculated $\mathrm{Hf}$ activity is compared with that required to form $\mathrm{HfO}_{2}$ at a $p_{\mathrm{O}_{2}}$ defined by the alloy $/ \mathrm{Al}_{2} \mathrm{O}_{3}$ equilibrium (which determines the Hf tolerance). The difference represents the driving force for $\mathrm{HfO}_{2}$ formation and is largest in the prior- $\gamma^{\prime}$ (color figure online).

$p_{\mathrm{O}_{2}}$ defined by the metal $/ \mathrm{Al}_{2} \mathrm{O}_{3}$ equilibrium. The difference between these two activities represents the driving force for $\mathrm{HfO}_{2}$ formation, and is seen to be the largest in the prior- $\gamma^{\prime}$. This local supersaturation is expected to favor preferential $\mathrm{HfO}_{2}$ nucleation. Close examination did not show any significant difference in the quantity of $\mathrm{HfO}_{2}$ precipitates between the regions identified as prior- $\gamma$ and prior- $\gamma^{\prime}$ (see Fig. 7b). An even shorter exposure might provide more conclusive results, although an added complication would be that this would necessarily be anisothermal.

Whether $\mathrm{Hf}$ oxidation occurred preferentially in prior- $\gamma^{\prime}$ regions or not, $\mathrm{HfO}_{2}$ particles were formed during a transient stage, before a steady-state was reached. By definition, this limits the applicability of an Hf tolerance criterion based solely on thermodynamic equilibrium. However, two limiting cases can be studied, defined by the initial and steady-state alloy composition at the metal/oxide interface. Qualitatively, in an alloy with an Hf content slightly below the tolerance calculated on the basis of the initial composition, removing $\mathrm{Al}$ by oxidation would rapidly lower the tolerance and cause $\mathrm{HfO}_{2}$ nucleation. The fact that $\mathrm{Hf}$ oxidized locally even in $\mathrm{Ni}-8 \mathrm{Cr}-17 \mathrm{Al}-0.05 \mathrm{Hf}$ (Figs. 4, 5) suggests that in the $\gamma-\gamma^{\prime}$ field, reducing the $\mathrm{Hf}$ concentration to a level where $\mathrm{HfO}_{2}$ is totally avoided is on the limit of being impractical, at least for the NiCrAl-Hf system considered in this study. A Calphadguided strategy to increase the Hf tolerance would be to judiciously add elements that either increase the fraction of $\gamma^{\prime}$ or have a negative interaction parameter such that they cause the Hf activity to decrease. Platinum is an example [31], but for 
most applications it is too expensive to be a viable alloying addition. Future work by our group is being directed at determining cost-effective alloying additions that act to decrease the Hf (and Y) activity in NiCrAl-based systems. It is noted, however, that a relatively high Hf tolerance is more easily sustained for single-phase $\gamma^{\prime}$ compositions.

\section{Conclusions}

A criterion based on thermodynamic equilibrium was devised to predict the $\mathrm{Hf}$ tolerance of $\mathrm{Hf}$-doped, $\mathrm{Al}_{2} \mathrm{O}_{3}$-forming $\mathrm{NiCrAl}$ alloys, i.e., the maximum amount of $\mathrm{Hf}$ that can be added without forming $\mathrm{HfO}_{2}$ beneath the $\mathrm{Al}_{2} \mathrm{O}_{3}$ scale. This criterion was applied considering the equilibrium composition of alloys in the $\gamma, \gamma-\gamma^{\prime}$ and $\gamma^{\prime}$ fields. Since the Hf solubility in $\gamma^{\prime}$ is larger than that in $\gamma$, the tolerance is predicted to increase with increasing $\gamma^{\prime}$ fraction.

The experimental results followed this trend, although some discrepancy existed: in particular, the model failed to account for localized $\mathrm{HfO}_{2}$ formation in $\gamma-\gamma^{\prime}$ alloys, i.e., it slightly overestimated the Hf tolerance. This is in part due to the fact that selective oxidation of $\mathrm{Al}$ causes $\gamma^{\prime}$ dissolution, which reduces the Hf tolerance. In addition, short-term oxidation tests showed that following $\gamma^{\prime}$ dissolution, a nonequilibrium situation prevailed in the subscale $\gamma$-band, where prior- $\gamma^{\prime}$ regions were supersaturated in Hf. The local rise in Hf activity increased the driving force for Hf oxidation. The specifics of $\mathrm{HfO}_{2}$ nucleation in this non-equilibrium state remain to be elucidated.

Routes for improving the tolerance criterion can be found in the thermodynamic model and in the boundary conditions chosen to represent the oxidation process. A more complete analysis would, for example, include the evolution of $\mathrm{HfO}_{2}$ solubility in $\mathrm{Al}_{2} \mathrm{O}_{3}$ with temperature, and account for the compositional changes due to $\mathrm{Hf}$ segregation to the metal surface as it is heated. Nevertheless, the approach adopted here proved useful in predicting the formation of micron-sized $\mathrm{HfO}_{2}$ particles, which may have adverse effects in practice, in terms of $\mathrm{Al}_{2} \mathrm{O}_{3}$ adhesion during thermal cycling or reactivity with molten sulfates. Future work to optimize reactive-element doping of NiCrAl-based systems includes the expansion of the thermodynamic model to other alloying elements.

\section{Acknowledgements}

This work was supported by the US Department of Energy through Grant DEFE0024056.

\section{References}

[1] D. P. Whittle and J. Stringer, Improvements in high temperature oxidation resistance by additions of reactive elements or oxide dispersions, Philosophical Transactions of the Royal Society of London A 295 (1980) pp. 309-329. doi: 10.1098/rsta.1980.0124. 
[2] H. Hindam and D. P. Whittle, Microstructure, adhesion and growth kinetics of protective scales on metals and alloys, Oxidation of Metals 18 (1982) pp. 245284. doi: $10.1007 / \mathrm{BF} 00656571$.

[3] J. Stringer, The reactive element effect in high-temperature corrosion, Materials Science and Engineering: A 120-121 (1989) pp. 129-137. doi: 10.1016/09215093(89)90730-2.

[4] D. P. Moon, Role of reactive elements in alloy protection, Materials Science and Technology 5 (1989) pp. 754-764. doi: 10.1179/mst.1989.5.8.754.

[5] R. Prescott and M. J. Graham, The formation of aluminum oxide scales on high-temperature alloys, Oxidation of Metals 38 (1992) pp. 233-254. doi: 10.1007/BF00666913.

[6] B. A. Pint, in Proceedings of the John Stringer Symposium on High Temperature Corrosion (P. F. Tortorelli et al., ed.) p. 9 ASM International, Materials Park, OH, USA (2003).

[7] B. A. Pint, Optimization of reactive-element additions to improve oxidation performance of alumina-forming alloys, Journal of the American Ceramic Society 86 (2003) pp. 686-695. doi: 10.1111/j.1151-2916.2003.tb03358.x.

[8] A. W. Funkenbusch, J. G. Smeggil and N. S. Bornstein, Reactive element-sulfur interaction and oxide scale adherence, Metallurgical Transactions A 16 (1985) pp. 1164-1166. doi: 10.1007/BF02811687.

[9] J. G. Smeggil, A. W. Funkenbusch and N. S. Bornstein, A relationship between indigenous impurity elements and protective oxide scale adherence characteristics, Metallurgical Transactions A 17 (1986) pp. 923-932. doi: $10.1007 / \mathrm{bf02661258.}$

[10] J. L. Smialek, Adherent $\mathrm{Al}_{2} \mathrm{O}_{3}$ scales formed on undoped $\mathrm{NiCrAl}$ alloys, Metallurgical Transactions A 18 (1987) pp. 164-167. doi: 10.1007/BF02646237.

[11] D. R. Sigler, Aluminum oxide adherence on $\mathrm{Fe}-\mathrm{Cr}-\mathrm{Al}$ alloys modified with group IIIB, IVB, VB, and VIB elements, Oxidation of Metals 32 (1989) pp. 337355. doi: $10.1007 / \mathrm{BF} 00665442$.

[12] J. L. Smialek and B. A. Pint, Optimizing scale adhesion on single crystal superalloys, Materials science forum 369-372 (2001) pp. 459-466. doi: 10.4028/www.scientific.net/MSF.369-372.459.

[13] P. Y. Hou, T. Izumi and B. Gleeson, Sulfur segregation at $\mathrm{Al}_{2} \mathrm{O}_{3} / \gamma-\mathrm{Ni}+\gamma$ '$\mathrm{Ni}_{3} \mathrm{Al}$ interfaces: Effects of $\mathrm{Pt}, \mathrm{Cr}$ and $\mathrm{Hf}$ additions, Oxidation of Metals 72 (2009) pp. 109-124. doi: 10.1007/s11085-009-9149-y.

[14] B. A. Pint and I. G. Wright, in Electrochemical Society Proceedings (P. Y. Hou et al., ed.) vol. 98-99 p. 263 Electrochemical Society, Pennington, NJ, USA (1998).

[15] J. D. Kuenzly and D. L. Douglass, The oxidation mechanism of $\mathrm{Ni}_{3} \mathrm{Al}$ containing yttrium, Oxidation of Metals 8 (1974) pp. 139-178. doi: 10.1007/BF00612170.

[16] Z. Tang and B. Gleeson, unpublished work.

[17] M. N. Task, B. Gleeson, F. S. Pettit and G. H. Meier, The effect of microstructure on the type II hot corrosion of Ni-base MCrAlY alloys, Oxidation of Metals 80 (2013) pp. 125-146. doi: 10.1007/s11085-013-9405-z. 
[18] T. Gheno and B. Gleeson, Modes of deposit-induced accelerated attack of MCrAlY systems at $1100{ }^{\circ} \mathrm{C}$, Oxidation of Metals 87 (2017) pp. 249-270. doi: 10.1007/s11085-016-9669-1.

[19] N. Dupin, I. Ansara and B. Sundman, Thermodynamic re-assessment of the ternary system Al-Cr-Ni, Calphad 25 (2001) pp. 279-298. doi: 10.1016/S03645916(01)00049-9.

[20] Materials Preparation Center, Ames Laboratory, US DOE Basic Energy Sciences, Ames, IA, USA, available from: www.ameslab.gov/mpc.

[21] N. Saunders and A. P. Miodownik, CALPHAD (Calculation of Phase Diagrams): A Comprehensive Guide. Elsevier (1998).

[22] T. Wang, Z. Jin and J.-C. Zhao, Experimental study and reassessment of the Ni-Hf binary system, Zeitschrift für Metallkunde 92 (2001) pp. 441-446.

[23] B. Sundman, B. Jansson and J. O. Andersson, The Thermo-Calc databank system, Calphad 9 (1985) pp. 153-190. doi: 10.1016/0364-5916(85)90021-5.

[24] J.-O. Andersson, T. Helander, L. Höglund, P. Shi and B. Sundman, ThermoCalc \& DICTRA, computational tools for materials science, Calphad 26 (2002) pp. 273-312. doi: 10.1016/S0364-5916(02)00037-8.

[25] Z. Li, Investigation of the Minor-Element Effects on the Oxidation Behavior of $\gamma-N i+\gamma^{\prime}-N i_{3} \mathrm{Al}$ Alloys. PhD thesis University of Pittsburgh (2015). http: //d-scholarship.pitt.edu/23418/.

[26] H. Y. Ku, Redistribution of solutes during thermal oxidation of silicon, Journal of Applied Physics 35 (1964) pp. 3391-3397. doi: 10.1063/1.1713227.

[27] D. Whittle, D. Evans, D. Scully and G. Wood, Compositional changes in the underlying alloy during the protective oxidation of alloys, Acta Metallurgica 15 (1967) pp. 1421-1430. doi: 10.1016/0001-6160(67)90173-3.

[28] B. D. Bastow, D. P. Whittle and G. C. Wood, Alloy depletion profiles resulting from the preferential removal of the less noble metal during alloy oxidation, Oxidation of Metals 12 (1978) pp. 413-438. doi: 10.1007/BF00612088.

[29] T. J. Nijdam, L. P. H. Jeurgens and W. G. Sloof, Modelling the thermal oxidation of ternary alloys - compositional changes in the alloy and the development of oxide phases, Acta Materialia 51 (2003) pp. 5295-5307. doi: 10.1016/S13596454(03)00381-1.

[30] J. A. Nesbitt and R. W. Heckel, Interdiffusion in Ni-rich, Ni-Cr-Al alloys at $1100{ }^{\circ} \mathrm{C}$ and $1200{ }^{\circ} \mathrm{C}$. II. Diffusion-coefficients and predicted concentration profiles, Metallurgical Transactions A-Physical Metallurgy and Materials Science 18 (1987) pp. 2075-2086. doi: 10.1007/bf02647079.

[31] B. Gleeson, W. Wang, S. Hayashi and D. Sordelet, Effects of platinum on the interdiffusion and oxidation behavior of Ni-Al-based alloys, Materials Science Forum 461-464 (2004) pp. 213-222. doi: 10.4028/www.scientific.net/MSF.461464.213. 